\title{
Aspergillus awamori ameliorates the physicochemical characteristics and mineral profile of mung bean under salt stress
}

\author{
Raid Ali ${ }^{1}$, Humaira Gul ${ }^{1}$, Muhammad Hamayun ${ }^{1}$, Mamoona Rauf ${ }^{1}$, Amjad lqbal ${ }^{2}{ }^{0}$, Mohib Shah', \\ Anwar Hussain ${ }^{1}$, Hamida Bibi ${ }^{3}$ and In-Jung Lee ${ }^{4^{*}}$
}

\begin{abstract}
Background: In the list of abiotic stresses, salt stress is a main growth retarding factor which affects $7 \%$ of rain-fed while 30\% worldwide irrigated agriculture. However, various strategies are assumed to manage this problem, but the use of endophytes is cheap and eco-friendly. The goal of this study was to evaluate the behavior of endophytic Aspergillus awamori (EWF) in creating salt tolerance in mung bean in terms of its seedling growth, biochemical indices, antioxidant enzymes, endogenous IAA, and ionic status of the plant.

Results: The results revealed that the $150 \mathrm{mM}$ of $\mathrm{NaCl}$ reduced seedling growth (seedlings' weight and length; leaves number), chlorophyll contents, and IAA. On the other hand, proline, polyphenols, flavonoids, tannin, lipid peroxidation, catalase, and ascorbate peroxidase were increased. Inoculation of EWF had promoted the mung bean growth under all tested conditions. EWF enhanced the biomass and IAA contents of the mung bean plants under salt stress. Moreover, EWF-associated mung bean seedlings exhibited low accumulation of stress markers, and $\mathrm{Cl}, \mathrm{Na}, \mathrm{Na} / \mathrm{K}$, and $\mathrm{Ca} / \mathrm{K}$ ratio, whereas higher concentrations of $\mathrm{Ca}, \mathrm{Mg}, \mathrm{K}, \mathrm{N}$, and $\mathrm{P}$ in mung bean seedlings.
\end{abstract}

Conclusion: The results provided a sustainable approach in using endophytic EWF under salt stress, thus concluded that this fungus can be very handy in mung bean as well as other important crop production in saline areas.

Keywords: Salinity, Mung bean, Endophytic fungi, Aspergillus awamori (EWF), IAA, lons

\section{Background}

Salinity greatly affects germination and vigor of the plant species, thus reduces the growth, development and yield of agricultural crops [20,31]. The presence of higher amounts of salts in soil may cause various metabolic and physiological disturbances [34, 44], which can lead to low yield and quality of grains. Moreover, it affects plant's survival percentage, germination of seeds, and various morphological characteristics [41]. Nutritional disorders, ions toxicity, and nutrients imbalance in cytosol have been noticed in plants due to transport and dispersion

\footnotetext{
*Correspondence: ijlee@knu.ac.kr

${ }^{4}$ School of Applied Biosciences, Kyungpook National University,

Daegu 41566, South Korea

Full list of author information is available at the end of the article
}

of high salt contents $[2,20]$. Besides, it leads to oxidative stress at cellular and subcellular level that generates ROS (reactive oxygen species). The produced ROS can then interfere with the metabolism of DNA, proteins, and lipids [40].

Mung beans (Vigna radiate) is a summer crop, which is cultivated in various regions of the Asia, Europe, and America [17, 36]. Mung bean is medicinally, yet nutritionally important crop and good for health [13]. Mung bean seeds comprise approximately $23-26 \%$ of protein, 61-63\% carbohydrates, and 1.1-1.6\% lipids [51], which is almost similar to the cowpea, lentil, and chickpea [26, 27]. Mung bean, like other legumes, is rich source of proteins, but salt stress can significantly affect the physicochemical quality of this crop [48]. Certainly, mung bean grown in saline soil can accumulate higher amounts of 
$\mathrm{NaCl}$ during its growth and development, leading to a low germination rate, protein and carbohydrate contents, and fresh and dry weights [43]. The studies suggested that mung bean being an important crop and very sensitive to salt stress needs proper action in order to restore its productivity. The development of salt resistant mung bean cultivars are very expensive and time consuming, whereas the use of plant growth promoting endophytes is quite feasible in saline areas.

Endophytes are microorganisms that live in the growing plant tissues and establish a symbiotic relationship with host plants $[22,25]$. They are broadly distributed in the plant kingdom, which produce a high number of biologically active secondary metabolites when required to support the host plants $[4,10,39]$. It has been noticed in the past that plant species colonized by endophytic fungi have managed stress environment, such as rise in temperature, salinity, and drought $[29,30,34]$. In addition, the host plant species exposed to stress developed an ability to absorb the required amounts of minerals from the soil after endophytic association [33]. Based on the previous findings and extreme importance of endophytic fungi in the field of agriculture, this study was conducted to test the role of endophytic fungal strain, Aspergillus awamori (EWF), in mung bean growth under normal and saline conditions.

\section{Materials and methods}

\section{Collections and purification of endophytic fungi} and preparation of spore suspension

Aspergillus awamori (EWF) was collected from the Plant Microbe Interaction Laboratory, Department of Botany, Abdul Wali Khan University Mardan. The strain was purified after repeated sub-culturing on potato dextrose agar (PDA) and incubated at $25^{\circ} \mathrm{C}$ for 2 weeks to produce a sufficient number of spores (conidia). The mycelia and spores formed on the PDA medium were scraped using a sterile No. 21 blade and placed in a $50-\mathrm{ml}$ sterile conical tube. $20 \mathrm{ml}$ of sterile water was added in the conical tube $(50 \mathrm{ml})$ and vortexed for $5 \mathrm{~min}$ for spore dispersion. The mixture (containing mycelia and spores) was then filtered with the help of Whatman filter paper No. 2 to obtain a spore suspension. The final concentration of spores in solution was adjusted to $5 \times 10^{7}$ spores $/ \mathrm{ml}$ to be used in further experiments.

\section{Experimental setup}

A pot experiment was conducted to determine the effect of A. awamori inoculation on mung bean growth. A completely randomized design was set up including the inoculation of mung bean with $A$. awamori. Seeds of mung bean cultivar Qalendar were obtained from ARI (Agriculture Research Institute) Tarnab, Peshawar. Seeds were subjected to the viability test before starting the experiment. Uniform seeds were selected and dipped in $0.1 \%$ mercuric chloride for $60 \mathrm{~s}$ for sterilization. The mercuric chloride seeds were then washed thrice with distilled water to remove any traces of mercuric chloride. A total of 12 plastic pots $(8.5 \mathrm{~cm}$ diameter and $12.5 \mathrm{~cm}$ deep) with a basal outlet for leaching purpose were arranged. The pots were filled with 300 grams of sandy loam soil ( sand $=74.8 \%$, silt $=11.9 \%$, and clay $=13.2 \%$ ), having electrical conductivity $=0.9 \mathrm{dS} / \mathrm{m}$ and $\mathrm{pH}=7.2$. The sterilized seeds were sown in the pots and allowed to germinate at $23 \pm 2{ }^{\circ} \mathrm{C}$. At seedling stage, a spore suspension of fungi at $1 \mathrm{ml} / \mathrm{g}$ was applied as a treatment in the required set of pots. After 5 days of spore suspension application, $\mathrm{NaCl}$ salt solution $(150 \mathrm{mM})$ was applied twice a week in all set of pots, except the controls (irrigated with tap water).

The experimental design had 4 sets of treatments, with three replications and each replicate consisted of five plants/pot:

Set I: Seedlings irrigated with $0 \mathrm{mM} \mathrm{NaCl}$;

Set II: Seedlings irrigated with $150 \mathrm{mM} \mathrm{NaCl}$;

Set III: Seedlings treated with fungal spores $(A$. awamori) and irrigated with $0 \mathrm{mM} \mathrm{NaCl}$;

Set IV: Seedlings treated with fungal spores (A. awamori) and irrigated with $150 \mathrm{mM} \mathrm{NaCl}$.

The experiment was proceeded up to 35 days and after the completion of the experiment, mung bean plants were harvested. Shoots and roots of the mung bean plants were separated, and soil particles from the roots were removed with great care. Firstly, the fresh weights of shoots and roots were measured. The shoots and roots were then oven dried for $72 \mathrm{~h}$ at $60^{\circ} \mathrm{C}$ and re-weighted to determine the dry weights.

\section{Chlorophyll and carotenoids}

Total chlorophyll and carotenoid contents of fresh leaf samples were estimated and calculated through a process as described by Maclachlan and Zalik [37]. Fresh leaf samples were ground in $3 \mathrm{ml}$ of acetone (80\%) using mortar and pestle. The mixture was transferred to the centrifuge tubes and centrifuged at $1000 \mathrm{rpm}$ for $5 \mathrm{~min}$. The supernatant was collected in the new tube and the pellet was washed again and centrifuged. The supernatant was pooled and adjusted the final volume to $7 \mathrm{ml}$ with acetone $(80 \%)$. The optical densities (OD) were recorded at $663 \mathrm{~nm}$ for chlorophyll a, $645 \mathrm{~nm}$ chlorophyll b, and 480 and $510 \mathrm{~nm}$ for carotenoids using UV/VIS spectrophotometer (Perkin Elmer):

Chlorophyll a $(\mathrm{mg} / \mathrm{g})=\left(\begin{array}{lllll}12.3 & \mathrm{D}_{663} & -0.86 & \mathrm{D}_{645} / \mathrm{d}\end{array}\right.$

*1000"w) $\times$ V;

Chlorophyll b $\quad(\mathrm{mg} / \mathrm{g})=\left(12.3 \quad \mathrm{D}_{645}-0.86 \quad \mathrm{D}_{663} / \mathrm{d}\right.$

*1000*w) $\times$ V; 
Total Chlorophyll $=$ Chla + Chlb;

Carotenoids $(\mathrm{mg} / \mathrm{g})=\left(7.6 \mathrm{D}_{480}-1.49 \mathrm{D}_{510} / \mathrm{D}^{*} 1000 * \mathrm{~W}\right)$

*V.

\section{Estimation of total carbohydrate}

Anthrone method was adopted for the estimation of total sugars in fresh leaf samples [54]. A $0.5 \mathrm{~g}$ of fresh leaf was crushed in $10 \mathrm{ml}$ of distilled water. After transferring the mixture in centrifuge tubes, a centrifugation was performed at $3000 \mathrm{rpm}$ for $5 \mathrm{~min}$. For the estimation of total carbohydrates, $0.1 \mathrm{ml}$ of the supernatant was mixed with $1 \mathrm{ml}$ phenol (80\%) and the mixture was incubated for $10 \mathrm{~min}$ at room temperature. After incubation, $5 \mathrm{ml}$ of concentrated $\mathrm{H}_{2} \mathrm{SO}_{4}$ was added and the mixture was incubated on the bench for an hour. Glucose was used as a standard and the OD of the solution was measured at $485 \mathrm{~nm}$.

\section{Estimation of total proteins}

Total proteins of mung bean plants were measured through well-defined method of Bradford [11]. $0.1 \mathrm{~g}$ of leaf sample was homogenized in ice-cold pestle and mortar using $5 \mathrm{ml}$ of phosphate buffer $(\mathrm{pH}=7,0.1 \mathrm{M}$ potassium phosphate). The mixture was centrifuged at $12,000 \mathrm{rpm}$ for $20 \mathrm{~min}$. To $0.2 \mathrm{ml}$ of the supernatant, $4.8 \mathrm{ml}$ of phosphate buffer was added. For the estimation of total proteins, $0.1 \mathrm{ml}$ of the diluted extract was taken in a clean test tube and added $5 \mathrm{ml}$ of Bradford reagent. Bovine serum albumin was used as a standard and the OD was then recorded at $595 \mathrm{~nm}$.

\section{Estimation of total lipids}

Total lipid contents were measured according to the wellestablished method of Van Handel [50]. Approximately, $0.2 \mathrm{~g}$ of leaf sample was ground in chloroform:methanol $(2: 1 \mathrm{v} / \mathrm{v})$ and the mixture was transferred to the tubes. The contents of each tube were shaken vigorously, added $0.8 \mathrm{ml}$ of $0.73 \% \mathrm{NaCl}$, and let it stand on the bench top at room temperature. After the appearance of three layers, the lower layer containing lipids were separated/collected through the separatory funnel. After separation of lipid layer, $0.1 \mathrm{ml}$ of sulfuric acid was added and the mixture was shaken and then heated at $100{ }^{\circ} \mathrm{C}$ for $10 \mathrm{~min}$. The sample was cooled and $2.4 \mathrm{ml}$ of vanillin reagent was added. Pure canola oil was used as a standard and the absorbance was recorded at $490 \mathrm{~nm}$ upon the appearance of pink color.

\section{Estimation of total proline}

Bates et al. [8] method for the extraction and estimation of proline in plants was adopted. Leaf sample $(0.5 \mathrm{~g})$ was ground in $10 \mathrm{ml}$ of sulfosalicyclic acid (3\%) and the mixture was centrifuged for $5 \mathrm{~min}$ at $3000 \mathrm{rpm}$. To $2 \mathrm{ml}$ of the collected supernatant in a glass tube, $2 \mathrm{ml}$ each of the glacial acetic-acid and freshly prepared ninhydrin reagent was added and the mixture was heated at $100{ }^{\circ} \mathrm{C}$ for an hour. The contents of the tube were cooled, $4 \mathrm{ml}$ of the toluene was added to it, and the mixture was vortexed vigorously. Pure proline from Sjima Aldrich was used as a standard and the OD was recorded at $520 \mathrm{~nm}$.

\section{Estimation of total phenolics}

Estimation of total phenols was carried using the wellestablished protocol of Malick and Singh [38] with slight modification. $0.5 \mathrm{~g}$ of leaf sample was ground in $80 \%$ ethanol $(5 \mathrm{ml})$ and the mixture was filtered through Whatman filter paper No. 1. The filtrate was evaporated to dryness and transferred to a $10-\mathrm{ml}$ glass tube. To the dried filtrate, $3 \mathrm{ml}$ of distilled water was added and the contents of the tube were vortexed. $0.5 \mathrm{ml}$ of Folin ciocalteu reagent and $2 \mathrm{ml}$ of $\mathrm{Na}_{2} \mathrm{CO}_{3}$ were added to the solution and mixed. After the appearance of the blue color, the contents were heated for $1 \mathrm{~min}$ and then allowed to cool. The absorbance of the solution was finally measured at $650 \mathrm{~nm}$. Catechol was used as a standard.

\section{Total flavonoids measurements}

Total flavonoids were measured by the method as described by El Far and Taie [16]. Approximately, $5 \mathrm{~g}$ of the leaf sample was macerated in $80 \%$ ethanol $(50 \mathrm{ml})$ for the preparation of extract. After 1 day of incubation at room temperature, the extract was centrifuged for $15 \mathrm{~min}$ at $10,000 \mathrm{rpm}$. To $250 \mu \mathrm{l}$ of the extract supernatant, $1.25 \mathrm{ml}$ of distilled water and $7 \mu \mathrm{l}$ of $\mathrm{NaNO}_{2}$ (5\%) were added and the mixture was incubated for $5 \mathrm{~min}$ at room temperature. After incubation, $150 \mu \mathrm{l}$ of $\mathrm{AlCl}_{3} \cdot \mathrm{H}_{2} \mathrm{O}$ $(10 \%)$ was added and the mixture was again incubated for $6 \mathrm{~min}$. After incubation, $500 \mu \mathrm{l}$ of $1 \mathrm{M}-\mathrm{NaOH}$ and $275 \mu \mathrm{l}$ of distilled water were added to the mixture and OD was recorded at $415 \mathrm{~nm}$. Quercetin was used as a standard.

\section{Determination of lipid peroxidation}

Heath and Packer [24] method was adopted for the determination of lipid peroxidation. Approximately, $0.1 \mathrm{~g}$ plant material was macerated in $2.5 \mathrm{ml}$ of $0.1 \%$ tricholoro acetic acid. The mixture was then transferred to centrifuge tubes and centrifuged for $20 \mathrm{~min}$ at $3000 \mathrm{rpm}$. The collected supernatant $(1 \mathrm{ml})$ was mixed with $2.25 \mathrm{ml}$ of $0.5 \%$ thiobarbituric acid and $20 \%$ tricholoro acetic acid. The mixture was heated at $95{ }^{\circ} \mathrm{C}$ for $30 \mathrm{~min}$, cooled in ice bath, and then centrifuged for $10 \mathrm{~min}$ at $3000 \mathrm{rpm}$. The OD of the collected supernatant was recorded at $532 \mathrm{~nm}$ and $600 \mathrm{~nm}$. Malondialdehyde was used as a standard. 


\section{Determination of catalase activity}

Catalase enzyme activity in fresh leaves was measured through protocol described by Chandlee and Scandalios [12]. Approximately, $1 \mathrm{~g}$ of leaf sample was homogenized in $2.6 \mathrm{ml}$ of $0.1 \mathrm{M}$ sodium phosphate buffer $(\mathrm{pH}=6.5)$ using pre-cooled mortar and pestle. A reaction mixture was made by mixing $0.1 \mathrm{ml}$ of enzyme extract with $1 \mathrm{ml}$ of potassium phosphate buffer $(100 \mathrm{mM}, \mathrm{pH}-7.0)$ and $0.4 \mathrm{ml} \mathrm{H}_{2} \mathrm{O}_{2}(200 \mathrm{mM})$. Reduction in absorbance due to decomposition of $\mathrm{H}_{2} \mathrm{O}_{2}$ was measured at 30-s intervals and $240 \mathrm{~nm}$.

\section{Determination of ascorbate peroxidases activity}

Asada [5] method with little modification was used for the measurement of the ascorbate peroxidase activity in fresh mung bean leaves. Approximately, $1 \mathrm{~g}$ of the leaf sample was ground in $3 \mathrm{ml}$ of extraction mixture containing phosphate buffer ( $\mathrm{pH} 7.0$ ), $10 \mathrm{mM} \mathrm{KCl}, 1 \mathrm{mM} \mathrm{MgCl}$, and $10 \mathrm{mM}$ EDTA. The ground mixture was centrifuged at $10,000 \mathrm{~g}$ for $20 \mathrm{~min}$ at $4{ }^{\circ} \mathrm{C}$ and the supernatant was collected as enzyme extract. The enzyme extract $(0.1 \mathrm{ml})$ was mixed with the reaction mixture $(0.9 \mathrm{ml})$, composed of ascorbic acid $(0.2 \mathrm{mM})+$ potassium phosphate buffer (50 mM, pH-7) + EDTA $(0.2 \mathrm{mM})+\mathrm{H}_{2} \mathrm{O}_{2}(20 \mathrm{mM})$. Reduction in optical density was measured at $290 \mathrm{~nm}$ and 30-second interval.

\section{Evaluation of endogenous IAA}

IAA was quantified using Salkowski reagent. Salkowski reagent was made by using the technique of Benizri et al. [9]. To prepare Salkowski reagent, $1 \mathrm{ml}$ of solution $\mathrm{A}\left(0.5 \mathrm{M} \mathrm{FeCl}_{3}\right)$ was mixed with $50 \mathrm{ml}$ of solution B $\left(35 \% \mathrm{HClO}_{4}\right)$. Plant material $(0.5 \mathrm{~g})$ was crushed by mortar and pestle in $5 \mathrm{ml}$ of distilled water and centrifuged at 10,000 rpm for $15 \mathrm{~min}$. The supernatant $(1 \mathrm{ml})$ was mixed with $2 \mathrm{~m} \mathrm{l}$ of Salkowski reagent in a test tube. The contents of the tube were incubated for $30 \mathrm{~min}$ in the dark at room temperature. Salkowski reagent $(4 \mathrm{ml})$ was used as a control. OD was taken at $540 \mathrm{~nm}$ using UV/VIZ spectrophotometer.

\section{Analysis of minerals}

Leaves sample $(0.25 \mathrm{~g})$, previously dried in an oven, was taken in a 50-ml flask. $6.5 \mathrm{ml}$ of acid solution consisting of nitric acid, sulfuric acid and perchloric acid (5:1:0.1) was added to it. The mixture was digested in a fume hood on a hot plate. Appearance of white fumes indicated the complete digestion of the sample. After the digestion, the contents of the digestion flask were allowed to cool. The cooled digest was collected in $50-\mathrm{ml}$ volumetric flasks and the volume was set to $50 \mathrm{ml}$ with distilled water. The extract was passed through the Whatman filter paper before quantifying the mineral elements by Atomic
Absorption Spectrophotometer (Shimadzu AA-670) (Allen et al. 1974).

\section{Statistical analysis}

All the experiments were performed in triplicate. ANOVA (one-way analysis of variance) was used for the analysis of data and means were compared by a Duncan multiple range test at $p<0.05$, using SPSS for windows 21.0 (SPSS Inc., Chicago, IL, USA). Graphs were constructed by using Graphpad Prism 6.0.

\section{Results}

\section{Seedling growth performance}

The results of the present study showed that the application of salt cause significant $(p=0.05)$ inhibition in plant growth (Fig. 1a and $b$ ). The mung bean plants that were irrigated with $\mathrm{NaCl}$ water had shorter shoots and roots as compared to the control plants. However, salt stress has less effect on the shoot and root growths of the Aspergillus awamori (EWF)-associated mung bean plants (Fig. 1a and b). Similarly, a considerable decrease was observed in the number of leaves in mung bean plants that were exposed to salt stress (Fig. 1c). On the other hand, the association of $A$. awamori with mung bean plants has a positive effect on the number of leaves under normal and saline conditions as compared to their respective controls (Fig. 1c). The effect of salt stress on dry biomass of the mung bean plants revealed an adverse effects (Fig. 1df). The dry weight of mung bean seedlings drastically decreased with $\mathrm{NaCl}$ treatment as compared to the control plants. On the contrary, enhancement in biomass of mung bean associated with $A$. awamori was noted under control and salt stress conditions (Fig. 1d-f).

\section{Response of pigments}

Results showed that the photosynthetic pigments (Chla, Chl-b, and total-chlorophyll) decreased significantly $(p=0.05)$ at elevated salt level $(150 \mathrm{mM} \mathrm{NaCl})$ in mung bean plants (Fig. 2). However, the ratio of $\mathrm{Chl}-\mathrm{a} / \mathrm{b}$ and the level of carotenoids were increased under salt stress as compared to the control. A. awamori association with mung bean restored the Chl-a, Chl-b, and total-chlorophyll contents, when exposed the plants to salt stress (Fig. 2).

\section{Accumulation of primary metabolites}

The results of the present study revealed a decrease in the total carbohydrates in mung bean under salt stress (Fig. 3a). Conversely, a beneficial effect of A. awamori on the amounts of carbohydrates of mung bean plants was observed under control as well as salt-stressed conditions (Fig. 3a). Additionally, treatment of mung bean with different concentrations of $\mathrm{NaCl}$ exhibited a 

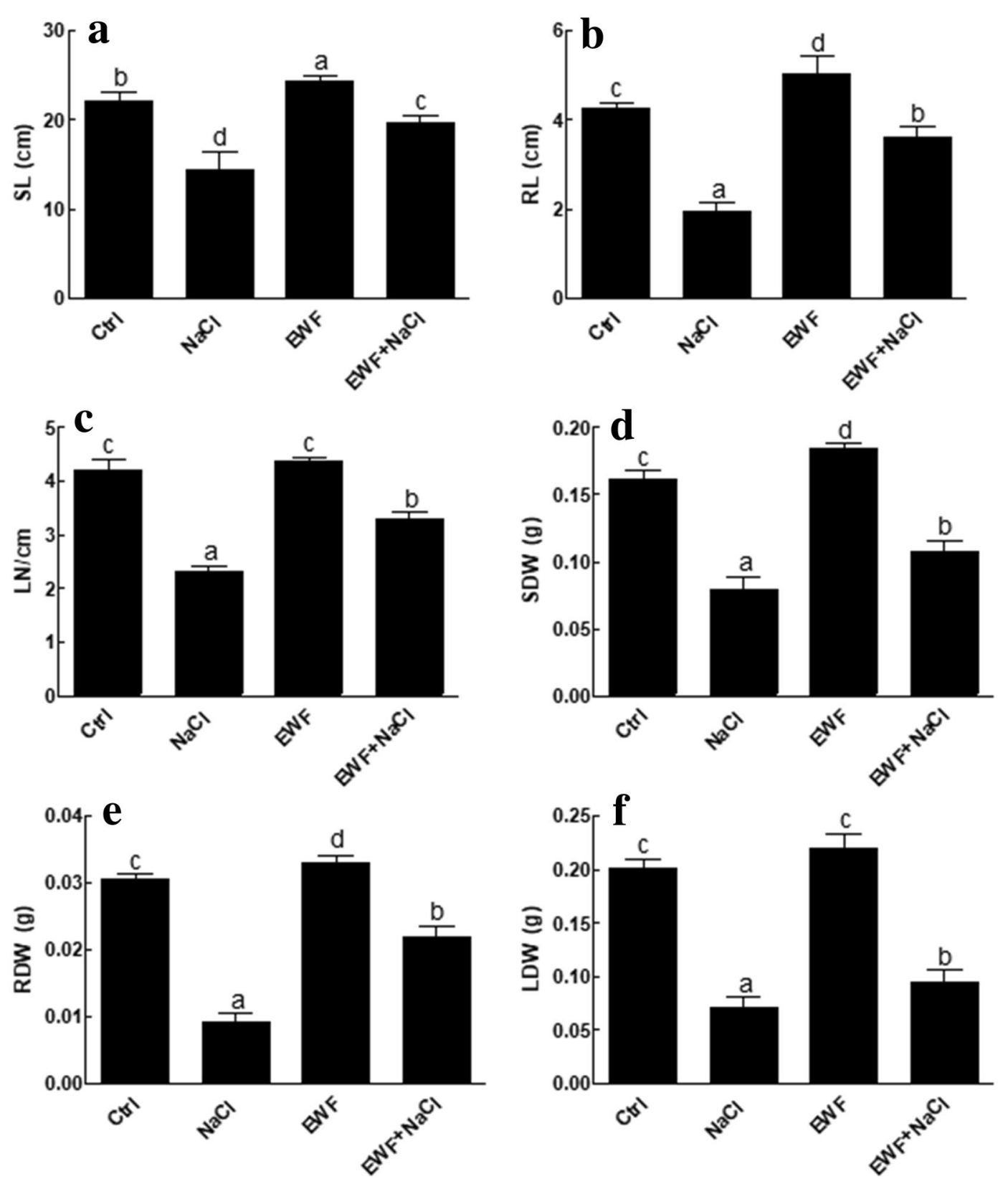

Fig. 1 Effect of $\mathrm{NaCl}$ on mung bean growth parameters with or without EWF association. a Shoot length; b Root length; $\mathbf{c}$ Leaf number; $\mathbf{d}$ Shoot dry weight; e Root dry weight; $\mathbf{f}$ Leaf dry weight. EWF: A. awamori-associated plants; Ctrl: control plants without A. awamori and salt stress; NaCl: sodium chloride-stressed plants without A. awamori association; EWF + NaCl: sodium chloride-stressed plants with A. awamori association; SL: shoot length; RL: root length; LN: leaf number; SDW: Shoot dry weight; RDW: root dry weight; LDW: leaf dry weight. Each bar represents the mean of triplicated data with \pm SE. Bars that are labeled with different letters are significantly different from one another at $p=0.05$

decrease in protein contents as compared to the other treatments (Fig. 3b). The application of the fungal strain (A. awamori), on the other hand, stimulated the accumulation of proteins in mung bean plants under normal and stressed conditions (Fig. 3b). Also, the
$\mathrm{NaCl}$ application significantly $(p=0.05)$ reduced the total lipid contents in mung bean plants as compared to the other treatments. However, a recovery in lipid contents of the mung bean plants has been noticed under saline conditions (Fig. 3c). 

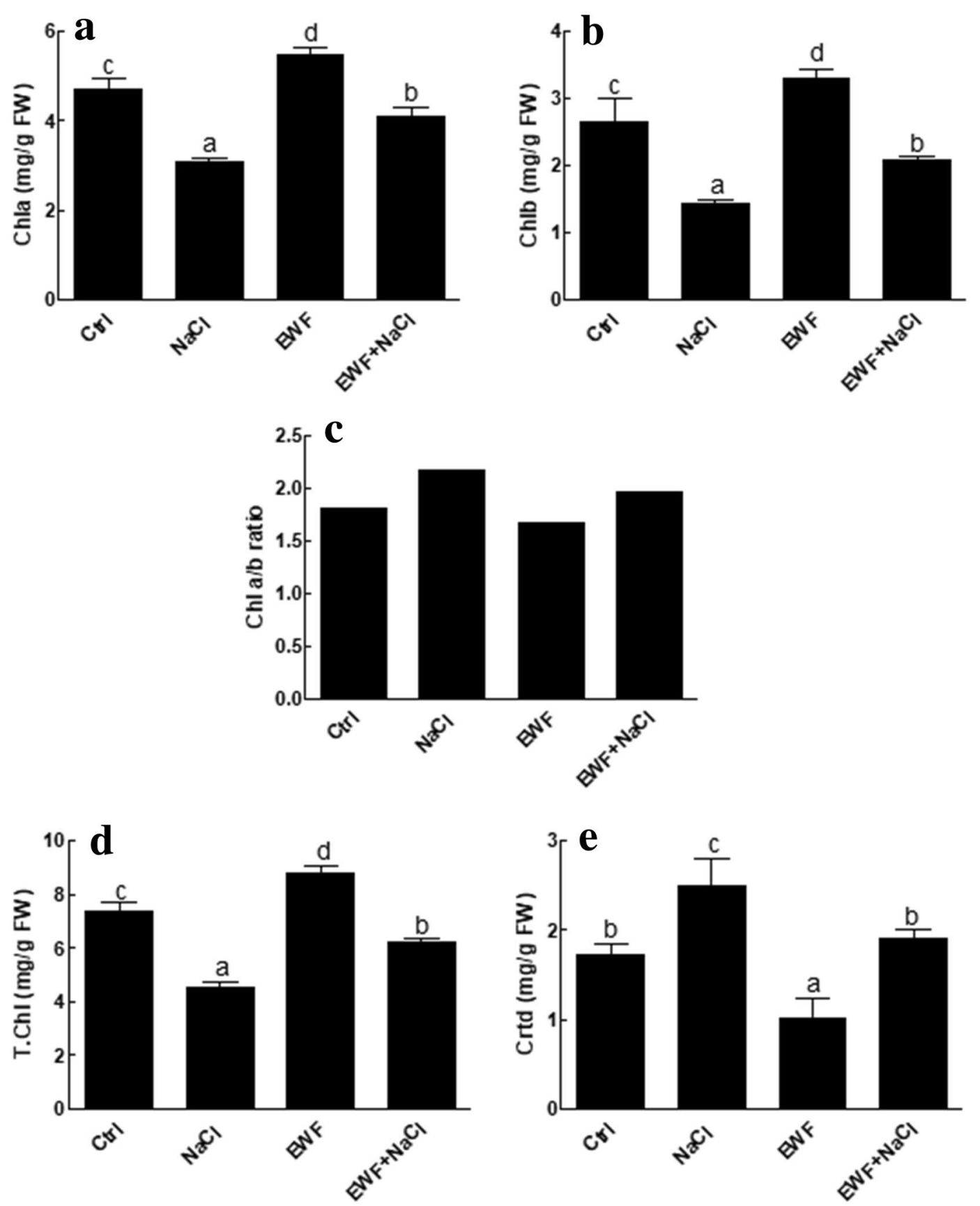

Fig. 2 Effect of $\mathrm{NaCl}$ stress on chlorophyll and carotenoid contents of mung bean seedlings with or without EWF association. a Chlorophyll a contents; b Chlorophyll b contents; c Ratio of chlorophyll a and chlorophyll b; d Total chlorophyll contents; e Carotenoid contents. EWF: A. awamori-associated plants; Ctrl: control plants without A. awamori and salt stress; $\mathrm{NaCl}$ : sodium chloride-stressed plants without A. awamori association; EWF + NaCl: sodium chloride-stressed plants with A. awamori association; Chla: chlorophyll a; Chlb: chlorophyll b; T.Chl: total chlorophyll; Crtd: carotenoids. Each bar represents the mean of triplicated data with \pm SE. Bars that are labeled with different letters are significantly different from one another at $p=0.05$

\section{Accumulation of secondary metabolites}

The results of this study exhibited a promotion in phenolic contents of the mung bean after application of salt stress. In contrast, the applied fungal endophytes ( $A$. awamori) brought the phenolic contents of the mung bean plants exposed to the salt stress back to normal 

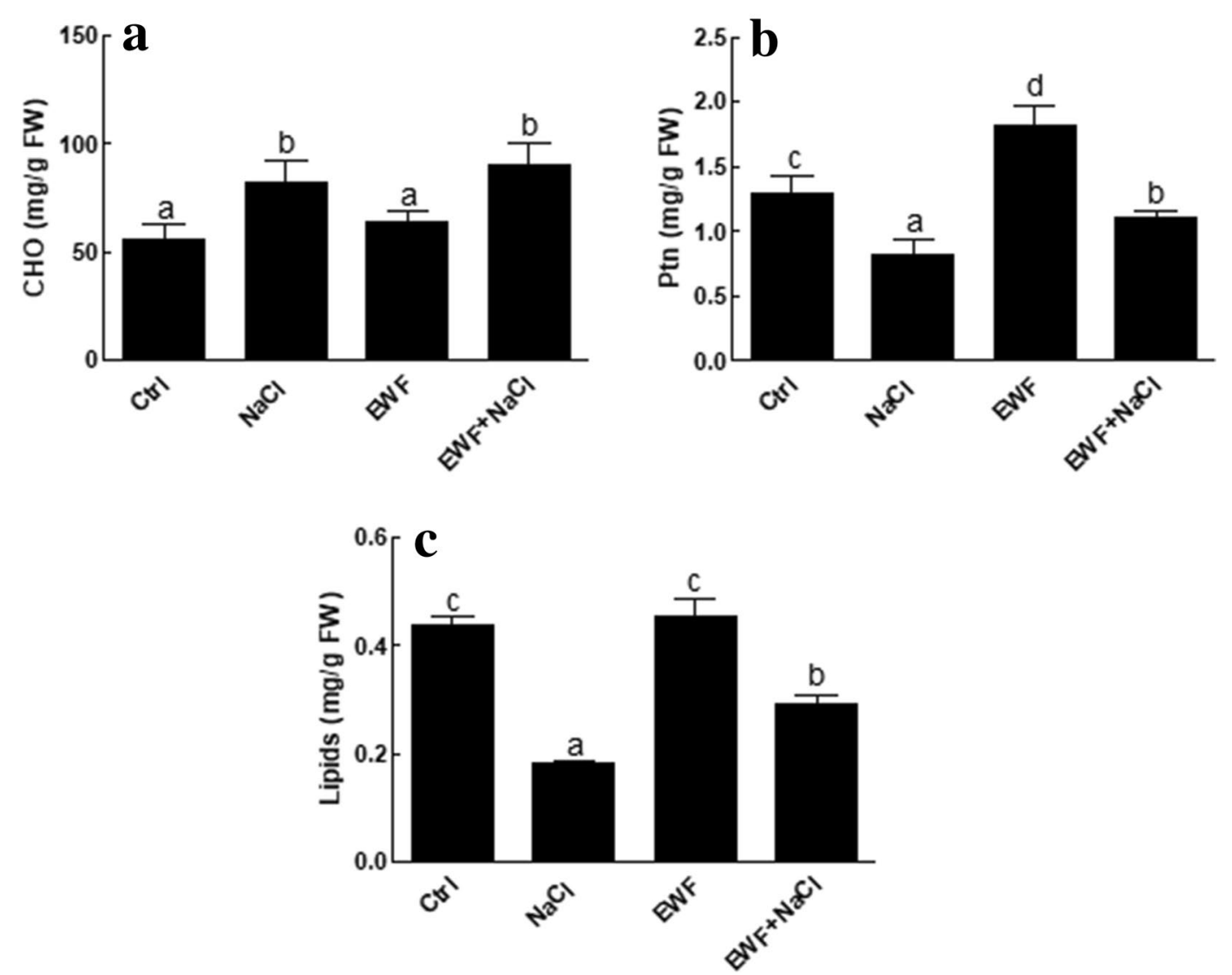

Fig. 3 Effect of $\mathrm{NaCl}$ stress on primary metabolites of mung bean seedlings with or without EWF association. a Carbohydrate contents; $\mathbf{b}$ Protein contents; c Lipid contents; EWF: A. awamori-associated plants; Ctrl: control plants without A. awamori and salt stress; NaCl: sodium chloride-stressed plants without A. awamori association; EWF + NaCl: sodium chloride-stressed plants with A. awamori association; CHO: carbohydrates; Ptn: proteins; FW: fresh weight. Each bar represents the mean of triplicated data with \pm SE. Bars that are labeled with different letters are significantly different from one another at $p=0.05$

(Fig. 4a). Likewise, the application of salt enhanced the accumulation of prolines in mung bean plants under salt stress as compared to the control plants, whereas less proline was accumulated in mung bean plants associated with A. awamori and exposed to salt stress (Fig. 4b). Moreover, salinity stress caused a significant increase in flavonoid content in mung bean plants, which was significantly $(p=0.05)$ reversed after the association of mung bean plants with $A$. awamori (Fig. 4c).

\section{Enzymatic activities}

The results revealed that the application of $\mathrm{NaCl}$ at different concentrations enhanced the lipid peroxidation in mung bean plants under salt stress conditions as compared to the control plants (Fig. 5a). The association of mung bean plants with endophyte (A. awamori), however, caused a significant reduction the lipid peroxidation at the tested concentrations of $\mathrm{NaCl}$ concentration (Fig. 5a). Also, an increased catalase activity has been noticed in the leaves of mung bean plants irrigated with $\mathrm{NaCl}$ solution as compared to the control plants (Fig. 5b). Conversely, the application of fungal endophyte $(A$. awamori) has played a positive role in controlling the catalase activity under normal and salt stress conditions. The $A$. awamori association enabled the mung bean plants to bring the catalase activity to normal (Fig. 5b). Besides, $\mathrm{NaCl}$ application has enhanced the activity of ascorbate peroxidase in mung bean plants, but the association of plants with $A$. awamori caused a significant decrease in ascorbic peroxidase under normal and salt stress environment (Fig. 5c).

\section{Endogenous IAA concentration}

After salt stress, the endogenous IAA content of the mung bean plants was reduced as compared to the control plants, but application of $A$. awamori improved the IAA concentration in mung bean plants during stress as well as non-stress conditions (Fig. 6). 

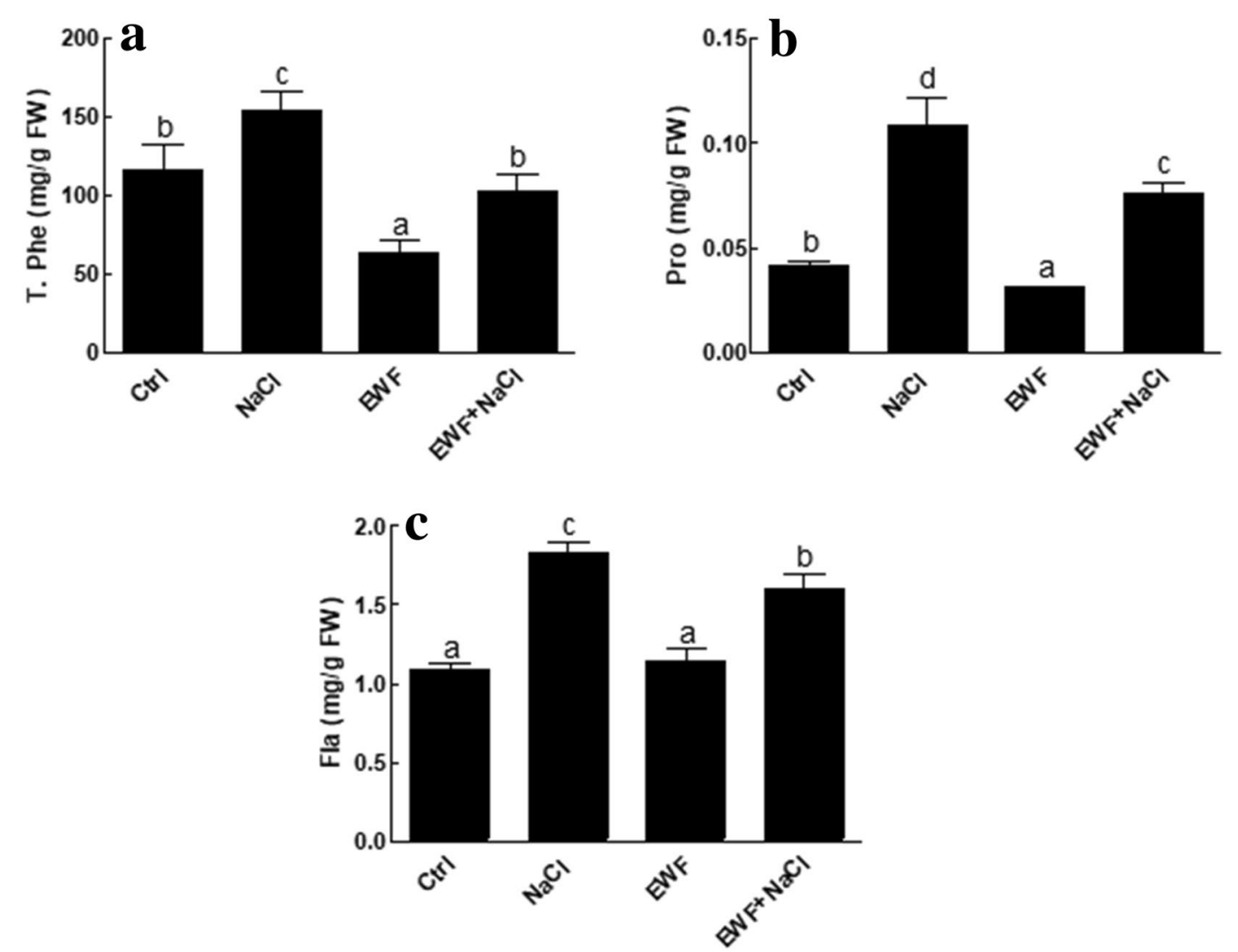

Fig. 4 Effect of $\mathrm{NaCl}$ on secondary metabolites of mung bean seedlings with or without EWF association. a Total phenolic contents; b Proline contents; c Flavonoid contents. EWF: A. awamori-associated plants; Ctrl: control plants without A. awamori and salt stress; NaCl: sodium chloride-stressed plants without A. awamori association; EWF + NaCl: sodium chloride-stressed plants with A. awamori association; T. Phe: total phenolics; Pro: proline; Fla: flavonoids; FW: fresh weight. Each bar represents the mean of triplicated data with \pm SE. Bars that are labeled with different letters are significantly different from one another at $p=0.05$

\section{Mineral contents of mung bean plant}

Our result showed an increase in sodium and chloride ion under salinity in mung bean seedlings (Table 1 ). Association of endophytic fungus (A. awamori) showed slightly decreases in sodium and enhance chloride ion. Salinity also caused a reduction in phosphorous, potassium, and calcium in mung bean plants, whereas less reduction was noticed in $A$. awamori-associated mung bean plants. Interestingly, an increase in $\mathrm{Na} / \mathrm{K}$ and $\mathrm{Na}$ / Ca ratios has been noticed in $A$. awamori-non-associated vs $A$. awamori-associated mung bean plants under saline conditions. The results also exhibited a decrease in nitrogen and magnesium levels in mung bean plants exposed to salt stress, while a reverse effect was observed in $A$. awamori-associated plants (Table 1).

\section{Discussion}

Substantial decrease in plant growth, vigor, and nutritional status have been noticed during biotic and abiotic stress conditions. Salt stress is one of the important and widespread stress that have visible effects related to various growth parameters of the plants, including shoot and root lengths. In the present study, a significant decrease was noticed in shoot lengths in the presence of high salt concentrations, whereas the effect on roots was there but mild. Conversely, the endophyte (A. awamori)-associated mung bean had significantly longer roots and shoot under normal condition as compared to the control. The reduction in shoot and root lengths under high $\mathrm{NaCl}$ concentrations can be linked to the ionic toxicity, which might lead to defects in cellular membranes of the mung bean cells [6]. In the last decade, the role of endophytes in plant growth and development under stressful conditions has been highlighted by various scientists [21, 30, 33, 41]. In recent years, Bacillus subtilis was noticed to restore the roots and shoots growth in Acacia gerrardii under saline conditions [23]. In fact, the endophytes have the ability to uphold the plants' fitness and normal health under harsh environment. 

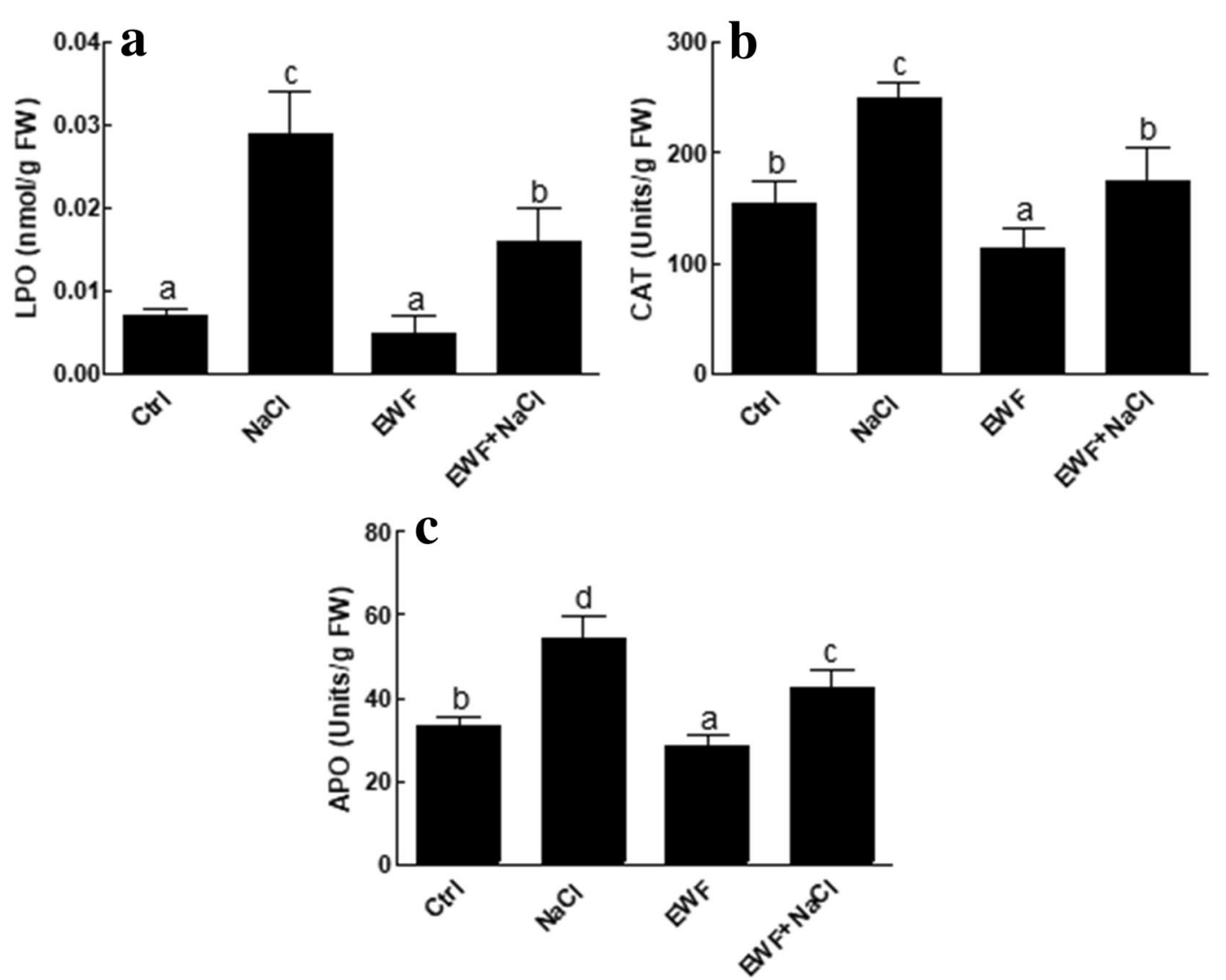

Fig. 5 Effect of $\mathrm{NaCl}$ on stress enzymes of mung bean seedlings with or without EWF association. a Lipid peroxidation activity; b Catalase activity; c Ascorbic acid peroxidase activity. EWF: A. awamori-associated plants; Ctrl: control plants without A. awamori and salt stress; NaCl: sodium chloride-stressed plants without A. awamori association; EWF + NaCl: sodium chloride-stressed plants with A. awamori association; LPO: Lipid peroxidation; CAT: catalase; APO: ascorbic acid peroxidase activity; FW: fresh weight. Each bar represents the mean of triplicated data with \pm SE. Bars that are labeled with different letters are significantly different from one another at $p=0.05$

In the current study, a considerable decrease in leaf number was noticed in mung bean plants exposed to salt stress. The decrease in leaf numbers might be due to the absorption of high salt concentrations by roots that can be transported to various tissues and finally accumulates in the cells, leading to low number of leaves. On the other hand, the application of $A$. awamori positively affected the leaf number of mung bean plants. This shows the helpful effect of $A$. awamori on mung bean plants under salt stress. The A. awamori might have the capability to absorb salt from the soil by itself and protect the host plants from the harmful effect of salts. Same phenomenon was observed in the past, where salt stress caused premature leaf senescence, thus leading to low number of leaves per plant [35]. Application of salt also caused severe reductions in mung bean biomass, Chl-a, Chlb, and total chlorophyll. Chl-a, Chl-b, and carotenoids are chief photosynthetic pigments that play vital role in the photosynthetic process. Various reasons can be responsible for severe reduction in biomass, Chl-a, Chl-b, and total-chlorophyll under salt stress, but declination in photosynthesis might be one of the major causes. Under saline condition, higher amounts of $\mathrm{Na}^{+}$can be accumulated in the chloroplast, which interferes with the PS-II and finally disrupts photosynthesis and inhibits growth of the plant [15]. Also, a reduction in the hydrolysis and translocation of reserved food to growing plant parts might be the possible answer to the significant decrease in plant biomass under salt stress. Higher accumulation of inorganic ions and organic solutes in plants under elevated salt concentrations might lead to reduction in plant dry matter [53]. The effect of salt stress on mung bean biomass, Chl-a, Chl-b, and total-chlorophyll have been reversed after the application A. awamori. Production of IAA might lead to an increased Chl-a, Chl-b, and totalchlorophyll contents in mung bean plants. Moreover, A. awamori inhibited the uptake of $\mathrm{Na}^{+}$and thus raised the chlorophyll and carotenoids contents in mung bean 


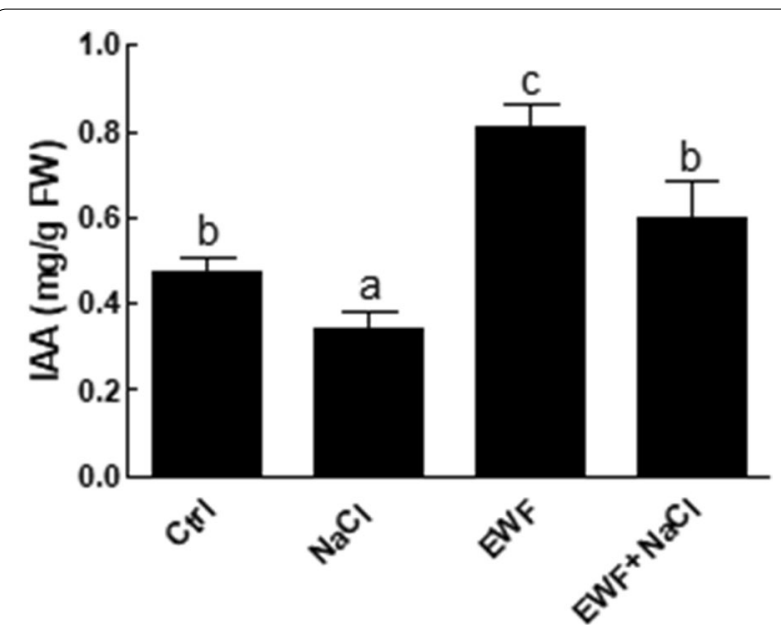

Fig. 6 Effect of $\mathrm{NaCl}$ stress on IAA of mung bean seedlings with or without EWF association. EWF: A. awamori-associated plants; $\mathrm{Ctrl}=$ control plants without $\mathrm{A}$. awamori and salt stress; $\mathrm{NaCl}$ : sodium chloride-stressed plants without $A$. awamori association; $\mathrm{EWF}+\mathrm{NaCl}$ : sodium chloride-stressed plants with A. awamori association; IAA: indole acetic acid; FW: fresh weight. Each bar represents the mean of triplicated data with \pm SE. Bars that are labeled with different letters are significantly different from one another at $p=0.05$

plants exposed to salt stress. Similar observations has been recorded by Muhammad et al. [41], they observed an increase in fresh biomass and dry biomass and chlorophyll contents of endophyte treated plants.

Under salt stress conditions, metabolic activities of the plant species get disturbed that might lead to the alteration in the levels of primary and secondary metabolites. The present study revealed a decrease in the total carbohydrates, proteins, and lipids and an increase in phenolics, flavonoids, and proline in salt-stressed mung bean. However, the A. awamori association has brought the primary and secondary metabolite concentrations back to normal in salt stressed mung bean plants. In fact in abiotic stress responses, soluble sugars are considered as a major marker [14]. The presence of high amounts of sugars in salt stress A. awamori-associated mung bean might be due to the protection against the oxidative damages at the molecular level. An increased amount of sugars have been noticed by Zhang et al. [55] in the endophyte-associated wheat plants grown under salt stress. Moreover, lipids and proteins are major components in cell membranes, which plays a major role in plant cell resistance against environmental stress. Salinity is widely reported to enhance production of ROS, which can damage important cell components, such as proteins, lipids, and nucleic acids [19]. The endophytes might have the ability to scavenge the ROS and ease the deleterious effect of the salt stress on host plants. Bagheri et al. [7] in this regard confirmed a significant promotion in total proteins and sugars in $P$. indica colonized rice plants under salt stress. Similarly, soybean was observed to retain the normal concentrations of sugars, proteins, and lipids in A. japonicas-associated plants [30].

Phenolic compounds are prevalent secondary metabolites in plants that play various roles and protection against ROS generated under environmental stresses. The results of the present study exhibited the production of high phenolic contents (33\%) in mung bean under salt stress. However, the applied fungal endophytes $(A$. awamori) regulated the production of the phenolics in the mung bean plants in the saline environment. Certainly, phenolic compounds can prevent membrane damages and scavenge the ROS during stress [49]. An increased production of phenolics has been observed in salt stressed pearl millets in recent years [34]. Proline is another stress marker and compatible organic solute with low molecular weight. Proline can serve as hydroxyl radical scavenger that can maintain water balance in cell and protect/stabilize macromolecules [23]. Proline contents of salt stressed mung bean plants were found high in the present study. Moreover, proline an osmoprotectant was regulated in mung bean plants associated with A. awamori. Plants can produce high proline contents during stress in order to increase water uptake

Table 1 Mineral profile of $A$. awamori-associated and $A$. awamori-non-associated mung bean seedlings under normal and salt stress conditions

\begin{tabular}{|c|c|c|c|c|c|c|c|c|c|}
\hline \multirow[t]{2}{*}{ Treatments } & \multicolumn{9}{|c|}{ Ionic status (mg/g DW) } \\
\hline & $\mathrm{Na}$ & $\mathrm{K}$ & $\mathrm{Ca}$ & $\mathrm{Mg}$ & $\mathrm{N}$ & $\mathbf{P}$ & $\mathrm{Cl}$ & $\mathrm{Na} / \mathrm{K}$ & $\mathrm{Na} / \mathrm{Ca}$ \\
\hline $\mathrm{Ctrl}$ & $14.0 \pm 0.1 \mathrm{c}$ & $22.2 \pm 0.8 b$ & $29.7 \pm 1.3 b$ & $7.8 \pm 0.3 b$ & $30.3 \pm 0.4 b$ & $2.1 \pm 0.9 c$ & $17.3 \pm 0.5 a$ & 0.63 & 0.47 \\
\hline $\mathrm{NaCl}$ & $53.8 \pm 1.7 d$ & $16.8 \pm 1.0 \mathrm{a}$ & $22.2 \pm 1.8 \mathrm{a}$ & $5.9 \pm 0.9 a$ & $19.4 \pm 0.7 a$ & $1.3 \pm 0.7 a$ & $50.3 \pm 1.1 \mathrm{c}$ & 3.23 & 2.43 \\
\hline EWF & $5.10 \pm 0.3 a$ & $33.0 \pm 0.7 d$ & $31.2 \pm 0.9 c$ & $10.9 \pm 1.9 d$ & $35.5 \pm 1.3 c$ & $2.1 \pm 1.7 \mathrm{c}$ & $17.9 \pm 0.6 a$ & 0.13 & 0.16 \\
\hline $\mathrm{EWF}+\mathrm{NaCl}$ & $12.9 \pm 0.7 b$ & $29.7 \pm 1.0 c$ & $30.8 \pm 1.1 \mathrm{~b}$ & $9.1 \pm 1.2 \mathrm{c}$ & $33.0 \pm 1.9 c$ & $1.7 \pm 0.2 b$ & $28.4 \pm 1.3 b$ & 0.4 & 0.41 \\
\hline
\end{tabular}

EWF: A. awamori-associated plants; Ctrl: control plants without A. awamori and salt stress; NaCl: sodium chloride-stressed plants without A. awamori association; $\mathrm{EWF}+\mathrm{NaCl}$ : sodium chloride-stressed plants with A. awamori association; DW: dry weight. Each data point represents the mean of triplicated data with $\pm \mathrm{SE}$. Data that are labeled with different letters are significantly different from their respective data point at $p=0.05$ 
and photosynthetic efficiency [3]. Our results are in line with the findings of Ismail et al. [28], who observed an increase in proline contents in endophyte inoculated soybean and sunflower plants under stress condition. High accumulation of proline in A. awamori-associated mung bean plants might help in retaining high leaf water contents under stress in order to protect them against oxidative damages. Correspondingly, flavonoids are nonenzymatic antioxidants that are known to scavenge toxic radicals during stress conditions [47]. The present results showed elevated level of flavonoids in mung bean under salt stress. Increase in flavonoid content at $150 \mathrm{mM} \mathrm{NaCl}$ was $68 \%$. The association of mung bean with A. awamori, on the other hand, regulated the flavonoid contents in mung bean plants during salt stress. Various reports confirmed an increased flavonoids contents in different plant species under stress $[21,44]$. In fact, plant activates different antioxidant systems, such as flavonoids and phenolics, to defend themselves against the ROS, produced during stresses. Furthermore, the high flavonoid contents permitted the $A$. awamori to scavenge ROS, generated during $\mathrm{NaCl}$ stress. Also, it is possible that A. awamori regulated the mung bean defense system to detoxify ROS and protect itself against the deleterious effect of high $\mathrm{NaCl}$ concentration.

Lipid peroxidation (LP) is defined as a non-enzymatic auto-oxidative process. This parameter is used as an indicator to assess plant's sensitivity to salt-induced oxidative stress [45]. In the present study, the application of $\mathrm{NaCl}$ showed high levels of LP in salt-stressed mung bean plants as compared to the other treatments. However, the application of $A$. awamori has regulated the LP in the mung bean plants undergoing salt stress. A. awamori might help the mung bean plants to activate their defense system to scavenge the ROS, thus reducing the LP. Similarly, Aspergillus terreus caused a significant reduction of LP in associated pearl millet plants at the tested $\mathrm{NaCl}$ concentrations [34]. Besides, catalase (CAT), and ascorbate per oxidase (APO) are antioxidant enzymes that can neutralize the harmful effect of ROS during stressful conditions. In the present study, it was observed that irrigation of mung bean with salt solution caused an increase in CAT and APO activities in leaves of mung bean plants as compared to the control. On the contrary, A. awamori normalized the CAT and APO activities in associated mung bean plants, experiencing salt stress. Indeed, catalase converts $\mathrm{H}_{2} \mathrm{O}_{2}$ to $\mathrm{H}_{2} \mathrm{O}$ and $\mathrm{O}_{2}$ and thus considered as the most effective enzyme to prevent oxidative damages in the plant body. In addition, APO enzyme neutralize the ROS and provide protection to plants. Neelam [42] explained that different environmental stresses, e.g., ionic stress and salt stress caused enhanced activity of catalase enzyme to neutralize $\mathrm{H}_{2} \mathrm{O}_{2}$.

\section{Endogenous IAA concentration}

The results of this study showed that the mung bean endogenous IAA content was reduced, when the plants were exposed to the salt stress. Reduction in values of IAA at high salt stress was approximately $27 \%$. An increase in IAA level has been noticed in mung bean plants associated with $A$. awamori under salt stress. Endophytes are known to help their host plants to release IAA under stress [4, 39]. Plant growth promotion under stressful conditions have been noticed by Mehmood et al. [39], which can be linked to the regulation of host plant's endogenous IAA by endophyte. $A$. awamori-associated plants also showed considerable IAA production, which supports the previous finding of Mehmood et al. [39].

Our result showed an increase level in sodium and chloride ions in mung bean seedlings under salinity, which was quite obvious. However, $A$. awamori-associated mung bean plants showed a significant $(p=0.05)$ decrease in sodium and chloride ion under salt stress. Zuccarini and Okurowska [56] explained that chloride ions accumulation during salt stress can be handled up to some extent after utilizing AM (arbuscular mycorrhiza). The AM helped in decreased uptake and accumulation of chloride ions. Similarly, AM was also found to revert the impact of high sodium [18]. Therefore, it might be possible that $A$. awamori absorbed the $\mathrm{NaCl}$ from the environment and protected it host from the negative effects of salt. Our results also showed that salinity caused a reduction in the level of potassium, calcium, magnesium, phosphorous, and nitrogen in mung bean plants. Opposingly, an increased level of potassium, calcium, magnesium, phosphorous, and nitrogen was noticed mung bean plants inoculated with $A$. awamori under salt stress. An AM-associated bean plants have also been observed to show resistance against the hazardous effects of salts. AM helped the bean plants to maintain ions balance, reduce deficiency of potassium and reduce $\mathrm{Na} / \mathrm{K}$ level [1]. Additionally, most crops absorb less phosphorus in high $\mathrm{NaCl}$ level present in soil. In the presence of salt, the absorption of phosphorous through roots and translocation through shoots are highly depressed which results in low crop yield. Moreover, Kalifa et al. [32] stated that inorganic phosphate is partly available during salt stress and this availability is crucial for developing salt tolerance in crops. So it might be possible that endophytic A. awamori released inorganic phosphate to help their host plants to regulate their normal metabolic process. Besides, rice seedlings grown in saline soil were observed to have low levels of nitrogen [52]. The low levels of nitrogen in rice grown under saline conditions might be linked to the disturbance in the ion homeostasis. In a previous study, it has been noticed that endophytic association 
enables the host plant to absorb more nitrogen in the form of nitrates under saline conditions [46].

\section{Conclusion}

From the results of this study, it is concluded that salt stress posed a severe a negative effect on mung bean growth and development. However, the use of endophytic fungi, $A$. awamori, reversed the negative effect and supported the growth of mung bean under salt stress. Therefore, A. awamori is one of the potential candidates that might be used as a biofertilizer to sustain agriculture under biotic and abiotic stress conditions.

\section{Acknowledgements}

The authors are thankful to the Abdul Wali Khan University Mardan and Kyungpook National University Korea for providing the lab facilities.

\section{Authors' contributions}

$\mathrm{RA}, \mathrm{HG}$, and MR designed and performed all the experiments. Al and $\mathrm{AH}$ analyzed the data and wrote the manuscript. $\mathrm{HG}$, IJL, and MH supervised the research. $\mathrm{Al}, \mathrm{IJL}$, and $\mathrm{MH}$ edited the manuscript and arranged the resources for the work. All authors read and approved the final manuscript.

\section{Funding}

This research was supported by the Basic Science Research Program through the National Research Foundation of Korea (NRF) funded by the Ministry of Education (2017R1D1A1B04035601).

\section{Availability of data and materials}

All the data are included in this manuscript.

\section{Ethics approval and consent to participate}

This study does not involve any human, animal or endangered species.

\section{Consent for publication}

No consent/approval at the national or international level or appropriate permissions and/or licenses for this study was required.

\section{Competing interests}

The authors declare that there is no competing interest of any nature related to this manuscript.

\section{Author details \\ 1 Department of Botany, Abdul Wali Khan University Mardan, Mardan, Pakistan ${ }^{2}$ Department of Food Science \& Technology, Abdul Wali Khan University Mardan, Mardan, Pakistan. ${ }^{3}$ Department of Soil \& Environmental Sciences, University of Agriculture Peshawar, Peshawar, Pakistan. ${ }^{4}$ School of Applied Biosciences, Kyungpook National University, Daegu 41566, South Korea.}

Received: 4 September 2020 Accepted: 4 January 2021

Published online: 10 February 2021

\section{References}

1. AbdAllah EF, Hashem A, Alqarawi AA, Bahkali AH, Alwhibi MS. Enhancing growth performance and systemic acquired resistance of medicinal plant Sesbania sesban (L.) Merr using arbuscular mycorrhizal fungi under salt stress. Saudi J Biol Sci. 2015;22:274-83.

2. Acosta-Motos JR, Ortuño MF, Bernal-Vicente A, Diaz-Vivancos P, SanchezBlanco MJ, Hernandez JA. Plant responses to salt stress: adaptive mechanisms. Agronomy. 2017;7:18.

3. Agami R, Medani R, Abd El-Mola I, Taha R. Exogenous application with plant growth promoting rhizobacteria (PGPR) or proline induces stress tolerance in basil plants (Ocimum basilicum L.) exposed to water stress. Int J Environ Agri Res. 2016;2:78.
4. Ali S, Khan SA, Hamayun M, labal A, Khan AL, Hussain A, Shah M. Endophytic fungi from Caralluma acutangula can secrete plant growth promoting enzymes. Fresenius Environ Bull. 2019;28:2688-96.

5. Asada K (1987) Production and scavenging of active oxygen in photosynthesis Photoinhibition, 227-287.

6. Astaneh RK, Bolandnazar S, Nahandi FZ, Oustan S. Effect of selenium application on phenylalanine ammonia-lyase (PAL) activity, phenol leakage and total phenolic content in garlic (Allium sativum L.) under $\mathrm{NaCl}$ stress. Inf Process Agric. 2018:5:339-44.

7. Bagheri AA, Saadatmand S, Niknam V, Nejadsatari T, Babaeizad V. Effect of endophytic fungus, Piriformospora indica, on growth and activity of antioxidant enzymes of rice (Oryza sativa L.) under salinity stress. Int J Adv Biol Biomed Res. 2013;1:1337-50.

8. Bates LS, Waldren RP, Teare I. Rapid determination of free proline for water-stress studies. Plant Soil. 1973;39:205-7.

9. Benizri E, Courtade A, Picard C, Guckert A. Role of maize root exudates in the production of auxins by Pseudomonas fluorescens M. Soil Biol Biochem. 1998:30:1481-4.

10. Bilal $\mathrm{L}$, et al. Plant growth promoting endophytic fungi Asprgillus fumigatus TS1 and Fusarium proliferatum BRL1 produce gibberellins and regulates plant endogenous hormones. Symbiosis. 2018;76:117-27. https ://doi.org/10.1007/s13199-018-0545-4.

11. Bradford MM. A rapid and sensitive method for the quantitation of microgram quantities of protein utilizing the principle of protein-dye binding. Anal Biochem. 1976:72:248-54.

12. Chandlee J, Scandalios J. Analysis of variants affecting the catalase developmental program in maize scutellum. Theor Appl Genet. 1984;69:71-7.

13. Dahiya P, Linnemann A, Van Boekel M, Khetarpaul N, Grewal R, Nout M. Mung bean: technological and nutritional potential. Crit Rev Food Sci Nutr. 2015;55:670-88.

14. de Azevedo Neto AD, Prisco JT, Enéas-Filho J, de Abreu CEB, Gomes-Filho E. Effect of salt stress on antioxidative enzymes and lipid peroxidation in leaves and roots of salt-tolerant and salt-sensitive maize genotypes. Environ Exp Bot. 2006;56:87-94.

15. Diao M, Ma L, Wang J, Cui J, Fu A, Liu H. Selenium promotes the growth and photosynthesis of tomato seedlings under salt stress by enhancing chloroplast antioxidant defense system. J Plant Growth Regul. 2014:33:671-82.

16. El Far M, Taie HA. Antioxidant activities, total anthocyanins, phenolics and flavonoids contents of some sweetpotato genotypes under stress of different concentrations of sucrose and sorbitol. Aust J Basic Appl Sci. 2009:3:3609-16.

17. Espín JC, García-Conesa MT, Tomás-Barberán FA. Nutraceuticals: facts and fiction. Phytochemistry. 2007;68:2986-3008.

18. Evelin H, Kapoor R, Giri B. Arbuscular mycorrhizal fungi in alleviation of salt stress: a review. Ann Bot. 2009;104:1263-80.

19. Gill SS, Tuteja N. Reactive oxygen species and antioxidant machinery in abiotic stress tolerance in crop plants. Plant Physiol Biochem. 2010:48:909-30.

20. Gul Jan F, et al. A promising growth promoting Meyerozyma caribbica from Solanum xanthocarpum alleviated stress in maize plants. Biosci Rep. 2019;39:1-15.

21. Hamayun $M$, et al. Gibberellins producing endophytic fungus Porostereum spadiceum AGH786 rescues growth of salt affected soybean. Front Microbiol. 2017:8:1-13.

22. Hamayun $M$, et al. Gibberellins producing endophytic fungus Porostereum spadiceum AGH786 rescues growth of salt affected soybean. Front Microbiol. 2017:8:686. https://doi.org/10.3389/fmicb.2017.00686.

23. Hashem A, Abd-Allah EF, Alqarawi AA, Al-Huqail AA, Wirth S, Egamberdieva D. The interaction between arbuscular mycorrhizal fungi and endophytic bacteria enhances plant growth of Acacia gerrardii under salt stress. Front Microbiol. 2016;7:1089.

24. Heath RL, Packer L. Photoperoxidation in isolated chloroplasts: I. Kinetics and stoichiometry of fatty acid peroxidation. Arch Biochem Biophy. 1968;125:189-98.

25. Ikram M, Ali N, Jan G, Jan FG, Rahman IU, labal A, Hamayun M. IAA producing fungal endophyte Penicillium roqueforti Thom., enhances stress tolerance and nutrients uptake in wheat plants grown on heavy metal contaminated soils. PLoS ONE. 2018;13:e0208150. https://doi. org/10.1371/journal.pone.0208150. 
26. Iqbal A, Ateeq N, Khalil IA, Perveen S, Saleemullah S. Physicochemical characteristics and amino acid profile of chickpea cultivars grown in Pakistan. J Foodserv. 2006;17:94-101.

27. Iqbal A, Khalil IA, Ateeq N, Khan MS. Nutritional quality of important food legumes. Food Chem. 2006;97:331-5.

28. Ismail, et al. Thermal stress alleviating potential of endophytic fungus Rhizopus oryzae inoculated to sunflower (Helianthus annuus L.) and soybean (Glycine max L.). Pak J Bot. 2020;52:5.

29. Ismail Hamayun M, Hussain A, Afzal Khan S, lqbal A, Lee I-J. Aspergillus flavus promoted the growth of soybean and sunflower seedlings at elevated temperature. Biomed Res Int. 2019. https://doi. org/10.1155/2019/1295457.

30. Ismail Hamayun M, Hussain A, lqbal A, Khan SA, Lee I-J. Endophytic fungus Aspergillus japonicus mediates host plant growth under normal and heat stress conditions. Biomed Res Int. 2018. https://doi. org/10.1155/2018/7696831.

31. Jan FG, Hamayun M, Hussain A, Jan G, Iqbal A, Khan A, Lee I-J. An endophytic isolate of the fungus Yarrowia lipolytica produces metabolites that ameliorate the negative impact of salt stress on the physiology of maize. BMC Microbiol. 2019;19:3. https://doi.org/10.1186/s12866-018-1374-6.

32. Kalifa A, Barthakur N, Donnelly D. Phosphorus reduces salinity stress in micropropated potato American journal of potato research. 2000;77:179-82.

33. Kang S-M, Hamayun M, Khan MA, Iqbal A, Lee I-J. Bacillus subtilis JW1 enhances plant growth and nutrient uptake of Chinese cabbage through gibberellins secretion. J Appl Bot Food Qual. 2019;92:172-8.

34. Khushdil F, Jan FG, Jan G, Hamayun M, labal A, Hussain A, Bibi N. Salt stress alleviation in Pennisetum glaucum through secondary metabolites modulation by Aspergillus terreus. Plant Physiol Biochem. 2019;144:127-34.

35. Kong X, Wang T, Li W, Tang W, Zhang D, Dong H. Exogenous nitric oxide delays salt-induced leaf senescence in cotton (Gossypium hirsutum L.). Acta Physiol Plant. 2016;38:61.

36. Liu B, Guo X, Zhu K, Liu Y. Nutritional evaluation and antioxidant activity of sesame sprouts. Food Chem. 2011:129:799-803.

37. Maclachlan S, Zalik S. Plastid structure, chlorophyll concentration, and free amino acid composition of a chlorophyll mutant of barley. Can J Bot. 1963;41:1053-62.

38. Malick C, Singh M. Ins plant enzymology and histo enzymology. New Delhi: Kalyani Publishers; 1980. p. 286.

39. Mehmood A, Hussain A, Irshad M, Hamayun M, Iqbal A, Khan N. vitro production of IAA by endophytic fungus Aspergillus awamori and its growth promoting activities in Zea mays. Symbiosis. 2019;77:225-35. https://doi. org/10.1007/s13199-018-0583-y.

40. Mittler R. ROS are good. Trends Plant Sci. 2017;22:11-9.

41. Muhammad I, et al. Trichoderma reesei improved the nutrition status of wheat crop under salt stress. J Plant Interact. 2019;14:590-602.

42. Neelam S. Enhancement of catalase activity under salt stress in germinating seeds of Vigna radiata. Asian Journal of Biomedical and Pharmaceutical Sciences. 2013;3:6-8.
43. Nikpour-Rashidabad N, Tavasolee A, Torabian S, Farhangi-Abriz S. The effect of biochar on the physiological, morphological and anatomical characteristics of mung bean roots after exposure to salt stress. Arch Biol Sci. 2019;71:321-7.

44. Nusrat B, et al. Cochliobolus sp acts as a biochemical modulator to alleviate salinity stress in okra plants. Plant Physiol Biochem. 2019;139:459-69. https://doi.org/10.1016/j.plaphy.2019.04.019.

45. Ozgur R, Uzilday B, Sekmen AH, Turkan I. Reactive oxygen species regulation and antioxidant defence in halophytes. Funct Plant Biol. 2013:40:832-47.

46. Richardson AE, Barea J-M, McNeill AM, Prigent-Combaret C. Acquisition of phosphorus and nitrogen in the rhizosphere and plant growth promotion by microorganisms. Plant Soil. 2009;321:305-39.

47. Sarwat $\mathrm{M}$, et al. Mitigation of $\mathrm{NaCl}$ stress by arbuscular mycorrhizal fungi through the modulation of osmolytes, antioxidants and secondary metabolites in mustard (Brassica juncea L.) plants. Front Plant Sci. 2016;7:869.

48. Sehrawat N, Yadav M, Sharma AK, Kumar V, Bhat KV. Salt stress and mungbean [Vigna radiata (L.) Wilczek]: effects, physiological perspective and management practices for alleviating salinity. Arch Agron Soil Sci. 2019;65:1287-301.

49. Singh A (2018) The physiology of salt tolerance in four genotypes of chickpea during germination.

50. Van Handel E. Rapid determination of total lipids in mosquitoes. J Am Mosq Control Assoc. 1985;1:302-4.

51. Varma A, Mishra S, Tripathi A, Shukla U. Biochemical composition and storage protein profiling of mungbean (Vigna radiata L. wilczek) cultivars. J Pharmacogn Phytochem. 2018;7:708-13.

52. Wang H, Wu Z, Zhou Y, Han J, Shi D. Effects of salt stress on ion balance and nitrogen metabolism in rice. Plant Soil Environ. 2012;58:62-7.

53. $X u X, X u H$, Wang $Y$, Wang $X, Q i u Y, X u B$. The effect of salt stress on the chlorophyll level of the main sand-binding plants in the shelterbelt along the Tarim Desert Highway. Chin Sci Bull. 2008;53:109-11.

54. Yemm E, Willis A. The estimation of carbohydrates in plant extracts by anthrone. Biochem J. 1954;57:508.

55. Zhang S, Gan Y, Xu B. Application of plant-growth-promoting fungi Trichoderma longibrachiatum T6 enhances tolerance of wheat to salt stress through improvement of antioxidative defense system and gene expression. Front Plant Sci. 2016;7:1405.

56. Zuccarini P, Okurowska P. Effects of mycorrhizal colonization and fertilization on growth and photosynthesis of sweet basil under salt stress. J Plant Nutr. 2008;31:497-513.

\section{Publisher's Note}

Springer Nature remains neutral with regard to jurisdictional claims in published maps and institutional affiliations.

\section{Submit your manuscript to a SpringerOpen ${ }^{\odot}$ journal and benefit from:}

- Convenient online submission

- Rigorous peer review

- Open access: articles freely available online

- High visibility within the field

- Retaining the copyright to your article

Submit your next manuscript at springeropen.com 